\title{
Economic TEHES-Tube Material Evaluation by Absorbability Index under O-S-Dimensions for Minimizing Global Warming and Air Pollution by Exploring Dominance Theory: Green Management Initiative
}

\author{
M. Prabhu ${ }^{\mathbb{D}},{ }^{1}$ Sri Yogi Kottala $\left(\mathbb{D},{ }^{2}\right.$ A. Anbazhagan $\mathbb{D}^{3},{ }^{3}$ and Anoop Kumar Sahu $\mathbb{D}^{4}$ \\ ${ }^{1}$ Department of Business Administration, College of Administration and Economics, Lebanese French University, Erbil, \\ Kurdistan, Iraq \\ ${ }^{2}$ SVKM's Narsee Monjee Institute of Management Studies (Jadcherla Campus), Hyderabad, India \\ ${ }^{3}$ Department of Management Studies, PSV College of Arts and Science, Puducherry, India \\ ${ }^{4}$ Department of Mechanical Engineering, School of Studies in Engineering and Technology, Guru Ghasidas Vishwavidyalaya, \\ Bilaspur, Chhattisgarh, India
}

Correspondence should be addressed to M. Prabhu; bordauprabhu@lfu.edu.krd

Received 19 May 2021; Accepted 27 December 2021; Published 31 January 2022

Academic Editor: Shien Hui

Copyright (C) 2022 M. Prabhu et al. This is an open access article distributed under the Creative Commons Attribution License, which permits unrestricted use, distribution, and reproduction in any medium, provided the original work is properly cited.

It is investigated that the Global Warming and Air Pollution (GWAP) issues are highly prioritized around the world. There is a high magnitude of contaminated hot heat $(\mathrm{CHH})$ from hot fluids such as contaminated water, oils, and mixed oils; toxic oils increase the GWAP ON emission. Such GWAP can be controlled by applying the methods-techniques for optimizing the energy processes, evaluating the high energy absorption material among available materials and technological advancement in energy flow devices, optimizing design of energy systems and low heat emission strategy, etc. It is observed that nowadays, Thermal Energy Heat Exchanger Systems (TEHESs) are utilized in many industries for transferring the energy between two mineral or contaminated liquids, separated by walls. It is found that TEHESs are constructed by tube materials, might be contributed to control the GWAP if TEHESs are fabricated with composite material, and have a high absorbability index. The evaluation of the Energy Absorbability Index (EAI) of TEHES composite tube materials provides the two innovative solutions to TEHES designers such as choose the economic/cost TEHESs and initiate to green management (reducing minimizing the GWAP). On literature survey, a few research documents are found by authors, which focused on mathematical modelling of either O- (objective-) or S- (subjective-) dimensions of composite TEHES tube material evaluation models for computing EAI. It is also probed that those models are simulated by single or nondynamic material evaluation methods. Therefore, it is summarized that there are no still research document pertaining to integrated/mixed mathematical modelling of O-S(objective-subjective-) dimensions of composite TEHES tube materials with dominance theory for computing EAI of composite TEHES tube materials. Said research gaps are respected as major research defies (help to minimize the GWAP or green management). To fulfil the said research defies, the authors developed and proposed the TEHES-O-S-composite tube material evaluation model by conducting literature and real industrial survey, consisting of seven TEHES-O and four TEHES-S tube material dimensions. The O-dimensions are framed by available O-rating/data, while S-dimension is framed S-rating. The TFNs (triangular fuzzy numbers) are used by a team of experts for assigning the appropriateness ratings vs. four TEHES-S composite tube material dimension, and priority weights are assigned vs. entire TEHES-O-S tube material dimensions. After data modelling of the TEHES-O-S-composite tube material evaluation model, defuzzification is carried out to normalize O-Sdata. Later, the authors' implemented integrated optimization technique "crisp VIKOR combined FMF technique" to evaluate the EAI of composite TEHES tube materials. As the reliability of results is an enormous concern, dominance theory is applied by conducting the comparative analysis among evaluated results and delivering the accurate and reliable results. The evaluated beast composite TEHES tube materials based on EAI linked to green management and economic concern of material. The research can be used by TEHES designers to minimize the GWAP across the universe. 


\section{Introduction and Literature Review}

It is seen that Energy Management (EM) always contributed to protect the universe from GWAP. Green management is respected as EM or clean environmental initiative, which focused on high energy resource utilization by many conduits such as energy loss projection by devices, high toxic energy absorption, and eco-friendly technology applications to save energy, reuse of energy, etc. Economic is dealing with cost analysis. TEHESs are found as a sizzling device in the context of EM. It is found that EM contributed to reduce the GWAP around the universe. TEHESs are used to transfer the heat from boiling fluid to gas (vapour), water, air, and other fluids (toxic or nontoxic in nature). During heat transfer in case of toxic hot fluids, the hot heat burns the environmental toxic particles, consequently emphasizing the GWAP. Therefore, to control or decrease GWAP, the TEHESs must be fabricated of well suit composite material and should have the strong EAI, so that heat transfer might occur without losing of $\mathrm{CHH}$ towards environment. TEHESs must be framed with the materials, which encompass the best, rich, and high EAI, and can address the green management cum economic aspects. Energy Absorbability (EA) is defined as a measure of the degree to which materials are capable to absorb of heat/ energy. EA of TEHES is defined as a capability of alloys or composites or proposed materials to absorb the heat/energy without emission of contaminated or noncontaminated $\mathrm{CHH}$ to environment during the circulation of fluids across TEHESs. EAI is defined as a measurement of overall performance of TEHESs against multiple energy protection, green management imitative indicators/measures. It is probed by scientists via empirical surveys as well as recent research documents that high EAI of TEHES materials extremely impact the performance of TEHESs; therefore, said materials aid TEHESs to produce the high energy transition between two separated toxic fluids without losing $\mathrm{CHH}$ to environments, indirectly helping to increase the green management and minimize the future GWAP vice versa.

It is investigated that millions of industries are the user of TEHESs. Every day millions of tons of toxic $\mathrm{CHH}$ emits from TEHESs, which causes the GWAP. The existed $\mathrm{CHH}$ is also mixed with earth, environmental nanoparticles, and burns it to be released to the universe. Therefore, such as daily phenomenon cannot be entirely controlled, however can be minimized. As we universally know, the evaluation of high EAI of composite materials for fabricating the TEHESs plays the significant function in the area of EM. The TEHES tube material evaluation against high EAI requires the $\mathrm{O}-\mathrm{S}$ (objective-subjective) dimension analysis simultaneously to become the potential device for reducing the GWAP. The dimensions that can be measured is called a set of objective $(\mathrm{O})$ dimensions. The dimensions that are vague in nature and cannot be measured are called a set of subjective (S) dimensions. In the recent research search, the authors found that a few research documents existed, which dealt with mathematical modelling of individual O-ph (objective) or S-ph (subjective) dimension models. Determined models are simulated by single or non-Morden material evaluation methods. Therefore, the authors ascer- tained that there are no still research document focused on mixed mathematical modelling of O-S- (objective-subjective-) dimension model with an integrated approach with dominance theory in the context of evaluating the EAI of composite TEHES tube material to control and minimize GWAP. To fulfil these research challenges, in the presented research work, the authors focused on right evaluation and selection of high EAI-TEHES tube material from available range of material alternatives, which aids TEHESs to minimize GWAP $[1,2]$.

In order to establish the O-S- (objective-subjective-) dimension model for assessing EAI of composite TEHES tube materials, the authors conducted the literature survey are revealed here.

The appropriate evaluation of high-EAI TEHES tube materials is a crucial task for the designers and operators [3-5]. Today, it is necessary to measure the EAI of TEHESs, which make TEHESs for attaining the nexus goal effectually and effectively. For the same, it is necessary to be alerted about various alternatives and criteria, satisfying the EAI of TEHES tube materials so that the best material can be used for fabricating the TEHESs. The criteria should analyze the performance of diverse TEHES tube materials vs. EAI and should evaluate fit TEHES tube material under EAI concerns [3]. Today, a large quantity of TEHES tube materials for designing TEHES with diverse properties is available, and hence, it is significant to adopt appropriately among available [6, 7]. The TEHES tube material evaluation under EAI issue is respected as a complicated and time-consuming task, and their selection will grace the several benefits such as help to attain the nexus goal $[6,8]$. TEHES tube material evaluation greatly interlinked the EA characteristics as said by [5, 9]. It is articulated that integration of potential technologies, heat absorbability of materials, etc., implicated by the practitioners into conventional working systems and the process of TEHESs, which reinforced the efficacy of conventional engineering systems and processes $[8,10]$. Today, material selection under EAI concern is becoming enormous dilemmas entailing the economic, social, and commercial aspects $[7,11]$.

Christian et al., [12] examined the mechanical, optical, and physical properties of Thermally Modified Timber (TMT) with its impact on high heat flow. Dang et al., [13] constructed a regularized solution of the source energy data prediction by using the interpolation and the truncated Fourier series method. [14] investigated the different effectiveness of heat and mass exchangers by using NTU correlation numerical models. The authors found that the effectiveness of heat and mass exchangers depends upon the evaluation and selection of conductive materials. Loganathan, A. and Ilangkumaran, M. [15] said that heat sink extensive material evaluation criteria must be formed for enhancing the reliability and life of modern heat devices. Thermal management devices are audited to verify the material evaluation model. Reeju P. [16] proposed new physical mechanisms for accurate material property predictions of materials to be used for heat generators. Uttamm and Mrinmoy [17] articulated that the performance and reliability of material's parameters that provide the higher 
operational efficiency for heat exchangers are examined by using the MCDM-NBO approach. Many physical dimensions are examined under investigation. [18] conducted the numerical analysis over the design evaluation of solar tower receiver under different parameters. The authors ascertained that material evaluation helps the solar tower receiver generate the high energy. It is determined that an appropriate selection of elevated TEHES tube materials is important for gracing the nexus goal, i.e., Air Pollution to Global Warming Zhengyi and Zheng [19]; Tripathi et al., [20]; Wang and Liu [21]; Aroon [22]; Wang [23], Girish et al., [24]. Systematic TEHES tube material selection processes require integration of optimization techniques and evaluation of life cycle behaviour of materials $[11,25]$. Multidimension integral and decision-making models encompass mathematical tools and can be utilized to evaluate and compare distinguish alternatives for supporting decision making under complex alternatives. After conducting a literature review, the authors proposed the TEHES material evaluation O-S dimension based model with the defuzzification-based crisp VIKOR-FMF-dominance theory approach to fulfil aforesaid research defies.

\section{Fuzzy Set towards Mathematical Framing of S-Dimensions of TEHES Tube Materials Assessing EAI}

The fuzzy set theory was introduced by Zadeh [26] to contract with the problems linking to vagueness and imprecise information. Triangular fuzzy numbers (TFNs) as presented by [27] is used in the presented research work for grasping ratings and weights of $\mathrm{O}-\mathrm{S}$ dimensions of composite TEHES tube materials. In the last decade, fuzzy logic has been successfully implicated in numerous practical applications. The fuzzy set theory works by way of engrossing numerical entities in engineering applications. Fuzzy sets assist in data handling and can be effectively engaged during system data processing [28]. The decision support model or frameworks are required to solve the issue of inserting fuzzy information into a system. Fuzzy evidently reach towards an acceptable range of solution after integrating series of extended operations. Fuzzy is considered as a mathematical modelling language by the researchers to approximate situations underlying conflicting criteria. The presented work utilized the arithmetic operations of triangular fuzzy numbers based on extension principle $[29,30]$.

Definition 1 (see Zadeh [26]). Fuzzy number. If a fuzzy set $A$ on the universe $R$ of real numbers satisfies the following conditions, we call it a fuzzy number.

(1) $A$ is a convex fuzzy set

(2) There is only one $x_{0}$ that satisfies $f_{A}\left(x_{0}\right)=1$

(3) $f_{A}(x)$ is continuous in an interval

Based on the extension principle, we can derive the arithmetic of fuzzy numbers as shown in ([30], Kaufmann and Gupta; 1991, [29]). Definition triangular fuzzy number: let $\tilde{B}=(a, b, c), a<b<c$, be a fuzzy set on $R=(-\infty$, $\infty)$. It is called a triangular fuzzy number if its membership function is

$$
\mu_{\tilde{B}}(x)=\left\{\begin{array}{l}
\frac{x-a}{b-a}, \text { if } a \leq x \leq b, \\
\frac{c-x}{c-b}, \text { if } b \leq x \leq c \\
0, \quad \text { otherwise. }
\end{array}\right.
$$

Obviously, we can treat the triangular fuzzy number $\tilde{B}=(a, b, c)$ as the trapezoid $(a, b, b, c)$.

$$
\begin{aligned}
& \tilde{a} \oplus \tilde{b}=\left(a_{1}, a_{2}, a_{3}\right) \oplus\left(b_{1}, b_{2}, b_{3}\right)=\left(a_{1}+b_{1}, a_{2}+b_{2}, a_{3}+b_{3}\right), \\
& \tilde{a}-\tilde{b}=\left(a_{1}, a_{2}, a_{3 \sim}\right)-\left(b_{1}, b_{2}, b_{3}\right)=\left(a_{1}-b_{4}, a_{2}-b_{3}, a_{3}-b_{2}\right), \\
& \tilde{a} \otimes \tilde{b}=\left(a_{1}, a_{2}, a_{3}\right) \otimes\left(b_{1}, b_{2}, b_{3}\right)=\tilde{a} \otimes \tilde{b} \\
& =\left(a_{1} \times b_{1}, a_{2} \times b_{2}, a_{3} \times b_{3}\right), \\
& \frac{\tilde{a}}{\tilde{\tilde{b}}} \frac{\left(a_{1}, a_{2}, a_{3}\right)}{\left(b_{1}, b_{2}, b_{3}\right)}=\left(\frac{a_{1}}{b_{3}}, \frac{a_{2}}{b_{2}}, \frac{a_{3}}{b_{1}}\right) .
\end{aligned}
$$

\section{Dominance Theory towards Evaluation of EAI of TEHES Tube Materials under O-S- Dimensions}

It is probed that each decision pertaining to reduce emission of $\mathrm{CHH}$ and contaminated matters fruitfully participate in controlling the GWAP and green management. The decision must be reliable. In worrying about such as matter, (Sahu et al., 2019) introduced the dominance theory. The motivation of authors to explore the dominance theory in the presented research work is to serve the defuzzification-based robust simulation-integrated technique (VIKOR-FMF) in solving the TEHES-O-S tube material evaluation model for assessing EAI of composite TEHES tube materials. The dominance theory instructed the authors to suggest the results with conducting the comparative analysis as the reliability of results is a concern.

Let $E=\left\{e_{1}, e_{2}, \cdots, e_{q}\right\}$ be the set of decision-makers in the group decision-making process. $A=\left\{A_{1}, A_{2}, \cdots, A_{m}\right\}$ be the set of alternatives, and $C=\left\{C_{1}, C_{2}, \cdots, C_{n}\right\}$ be the set of criteria attributes. Then, the TFN-aggregated fuzzy rating of alternatives with respect to each criterion can be defined as

$$
\widetilde{\tilde{x}}_{i j k}=\left(a_{i j}, b_{i j}, c_{i j}\right) \text {, }
$$

where

$$
a_{i j}=\frac{1}{K} \sum_{k=1}^{K} a_{i j k}
$$


TABLE 1: Developed and proposed TEHES-O-S-composite tube material evaluation model for assessing EAI and controlling the GWAP.

\begin{tabular}{|c|c|c|c|c|}
\hline Model & Nature of characteristics & Characteristics & Symbols & Units \\
\hline \multirow{11}{*}{$\begin{array}{l}\text { Energy Absorbability } \\
\text { Index (EAI) }\end{array}$} & \multirow{7}{*}{$\begin{array}{c}\text { Objective } \\
\text { (O-dimensions) }\end{array}$} & Yield strength on contaminated hot heat transfer & Yschht & $\mathrm{N} / \mathrm{m}^{2}$ \\
\hline & & Ultimate tensile strength on contaminated hot heat transfer & Utschht & $\mathrm{N} / \mathrm{m}^{2}$ \\
\hline & & Tube material elongation on contaminated hot heat transfer & $\%$ Eht & $\%$ \\
\hline & & Hardness tendency on contaminated hot heat transfer & Htchht & BHN \\
\hline & & Cost & $\mathrm{C}$ & $\mathrm{INR} / \mathrm{kg}$ \\
\hline & & Corrosion rate reduction on contaminated hot heat transfer & Crrchht & $\%$ \\
\hline & & Wear rate on contaminated hot heat transfer & Wrchht & $\mathrm{m}^{3} / \mathrm{m}$ \\
\hline & \multirow{4}{*}{$\begin{array}{c}\text { Subjective } \\
\text { (S-dimensions) }\end{array}$} & Tube material molecular excitement for heat absorbability & Tmmeha & Unit less \\
\hline & & Contaminated hot heat reduction to environment & Chhre & Unit less \\
\hline & & Contaminated hot heat transfer efficiency & Chhte & Unit less \\
\hline & & Contaminated hot heat transfer effectiveness & Chhtes & Unit less \\
\hline
\end{tabular}

TABLE 2: TEHES-O-S-tube material dimensions.

\begin{tabular}{|c|c|c|c|c|c|c|c|c|c|c|c|}
\hline \multirow{3}{*}{$\begin{array}{l}\text { Composite TEHES } \\
\text { tube material } \\
\text { evaluation }\end{array}$} & \multicolumn{11}{|c|}{ TEHES-O-S-ph tube material evaluation dimensions assessing HOI } \\
\hline & \multicolumn{7}{|c|}{ O-ph-data } & \multicolumn{4}{|c|}{ S-ph-data } \\
\hline & Yschht & Utschht & $\%$ Eht & Htchht & $\mathrm{C}$ & Crrchht & Wrchht & Tmmeha & Chhre & Chhte & Chhtes \\
\hline $\mathrm{J} 4$ & 382 & 728 & 48 & 98 & 112 & 0.16 & 2.75 & $F$-variable & $F$-variable & $F$-variable & $F$-variable \\
\hline JSLAUS & 420 & 790 & 58 & 97 & 210 & 0.31 & 2.63 & $F$-variable & $F$-variable & $F$-variable & $F$-variable \\
\hline $\mathrm{J} 204 \mathrm{Cu}$ & 415 & 795 & 55 & 96 & 120 & 0.05 & 2.5 & $F$-variable & $F$-variable & $F$-variable & $F$-variable \\
\hline $409 \mathrm{M}$ & 270 & 455 & 32 & 78 & 184 & 0.4 & 4 & $F$-variable & $F$-variable & $F$-variable & $F$-variable \\
\hline$J-304$ & 256 & 610 & 60 & 86 & 89 & 0.01 & 2.59 & $F$-variable & $F$-variable & $F$-variable & $F$-variable \\
\hline
\end{tabular}

$$
\begin{gathered}
b_{i j}=\frac{1}{K} \sum_{k=1}^{K} b_{i j k}, \\
c_{i j}=\frac{1}{K} \sum_{k=1}^{K} c_{i j k} .
\end{gathered}
$$

Then, the aggregated fuzzy weight of each criterion can be defined as

$$
\widetilde{\tilde{w}}_{j}=\left(w_{j 1}, w_{j 2}, w_{j 3}\right)
$$

where

$$
\begin{aligned}
& w_{j 1}=\frac{1}{K} \sum_{k=1}^{K} w_{k j 1}, \\
& w_{j 2}=\frac{1}{K} \sum_{k=1}^{K} w_{k j 2}, \\
& w_{j 3}=\frac{1}{K} \sum_{k=1}^{K} w_{k j 3} .
\end{aligned}
$$

3.1. Defuzzification. The defuzzification is the technique, which is employed to convert the TFN fuzzy elements into the crisp value for evaluating and comparing the alternatives. [31] described the three main approaches as the max criteria, mean of maximum, and the centre of area.
TABLE 3: The scale for assigning ratings for O-dimensions and weights for O-S-ph-dimensions.

\begin{tabular}{lccc}
\hline Linguistic & Rating variables & Weights variables & Rating/weights \\
\hline Very poor & $\mathrm{VP}$ & $\mathrm{ML}$ & $(0,0,3)$ \\
Poor & $\mathrm{P}$ & $\mathrm{M}$ & $(0,3,5)$ \\
Fair & $\mathrm{F}$ & $\mathrm{MH}$ & $(2,5,8)$ \\
Good & $\mathrm{G}$ & $\mathrm{H}$ & $(5,7,10)$ \\
Very good & $\mathrm{VG}$ & $\mathrm{VH}$ & $(7,10,10)$ \\
\hline
\end{tabular}

The center of gravity method to convert the triangular fuzzy set $(A, B ; C)$ into the measured or crisp value form [31]:

$$
\frac{A+4 B+C}{6}
$$

3.2. VIKOR-Technique-1. VIKOR stands for VIseKriterijumska Optimizacija I Kompromisno Resenje. The technique ranks the alternatives and determines the solution named compromise that is the closest to the ideal. VIKOR as presented by [27], is used in the presented research work for defining the appropriate high EAI of composite TEHES tube material alternatives, which can help for controlling the GWAP. VIKOR considers the expert's preference to review the dimensions of composite TEHES tube materials [32]. The VIKOR was recently developed as a one of multidimension integral and decision making of the complex system, which 


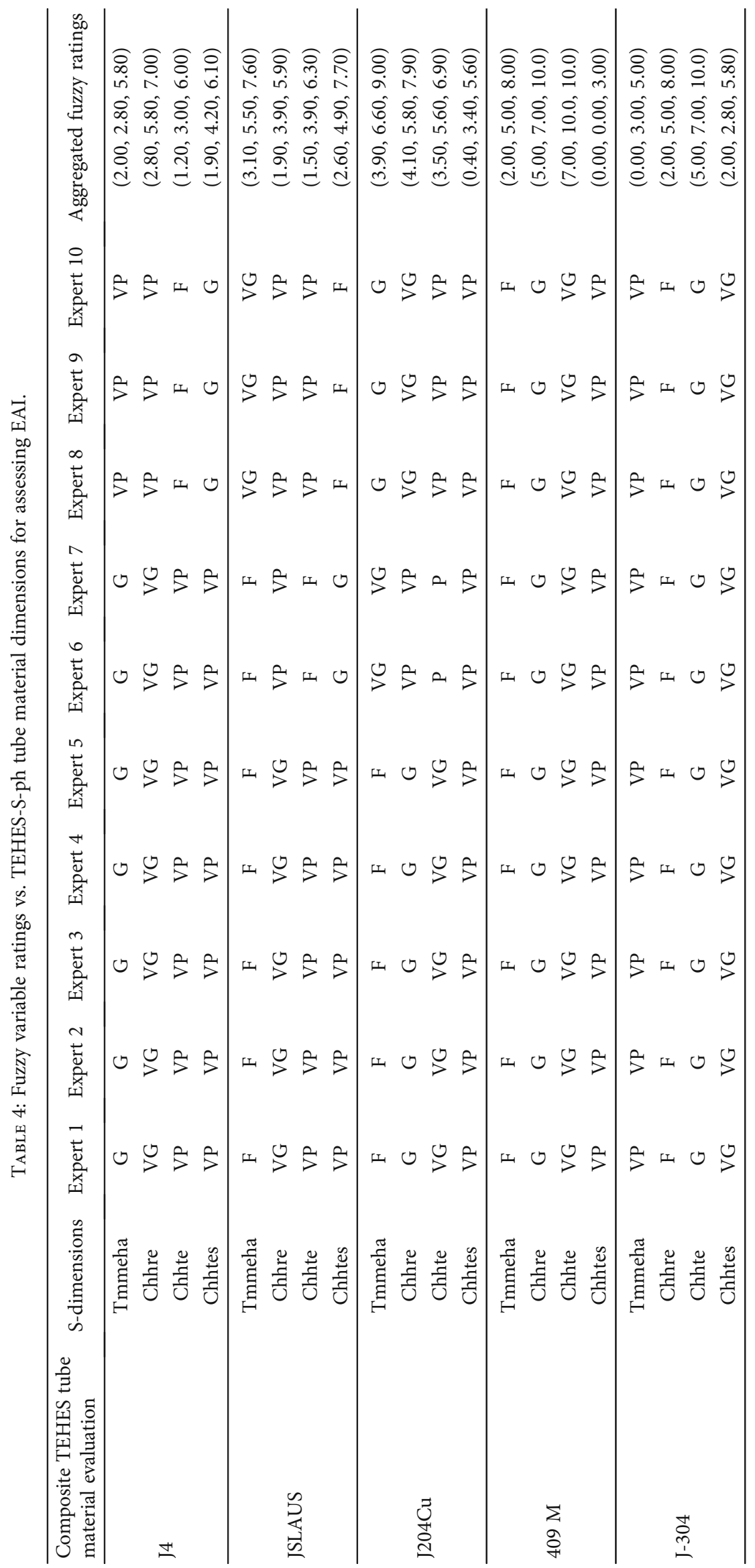


TABle 5: Fuzzy weight vs. TEHES-O-S-tube material dimensions for assessing EAI.

\begin{tabular}{lccccccccccc}
\hline O-S-dimensions & Expert 1 & Expert 2 & Expert 3 & Expert 4 & Expert 5 & Expert 6 & Expert 7 & Expert 8 & Expert 9 & Expert 10 & $\begin{array}{c}\text { Aggregated } \\
\text { fuzzy weight }\end{array}$ \\
\hline Yschht & $\mathrm{ML}$ & $\mathrm{M}$ & $\mathrm{H}$ & $\mathrm{MH}$ & $\mathrm{VH}$ & $\mathrm{M}$ & $\mathrm{MH}$ & $\mathrm{VH}$ & $\mathrm{ML}$ & $\mathrm{H}$ & $(2.80,5.00,7.20)$ \\
Utschht & $\mathrm{H}$ & $\mathrm{H}$ & $\mathrm{MH}$ & $\mathrm{H}$ & $\mathrm{ML}$ & $\mathrm{H}$ & $\mathrm{H}$ & $\mathrm{ML}$ & $\mathrm{H}$ & $\mathrm{MH}$ & $(3.10,5.10,7.70)$ \\
\% Eht & $\mathrm{VH}$ & $\mathrm{H}$ & $\mathrm{VH}$ & $\mathrm{M}$ & $\mathrm{VH}$ & $\mathrm{H}$ & $\mathrm{M}$ & $\mathrm{VH}$ & $\mathrm{VH}$ & $\mathrm{VH}$ & $(3.80,6.00,7.60)$ \\
Htchht & $\mathrm{M}$ & $\mathrm{M}$ & $\mathrm{H}$ & $\mathrm{H}$ & $\mathrm{H}$ & $\mathrm{M}$ & $\mathrm{H}$ & $\mathrm{H}$ & $\mathrm{M}$ & $\mathrm{H}$ & $(2.50,4.70,7.30)$ \\
C & $\mathrm{ML}$ & $\mathrm{ML}$ & $\mathrm{ML}$ & $\mathrm{M}$ & $\mathrm{M}$ & $\mathrm{ML}$ & $\mathrm{M}$ & $\mathrm{M}$ & $\mathrm{ML}$ & $\mathrm{ML}$ & $(1.40,3.40,5.70)$ \\
Crrchht & $\mathrm{H}$ & $\mathrm{VH}$ & $\mathrm{MH}$ & $\mathrm{H}$ & $\mathrm{MH}$ & $\mathrm{VH}$ & $\mathrm{H}$ & $\mathrm{MH}$ & $\mathrm{H}$ & $\mathrm{MH}$ & $(2.80,5.20,7.70$ \\
Wrchht & $\mathrm{M}$ & $\mathrm{ML}$ & $\mathrm{M}$ & $\mathrm{M}$ & $\mathrm{ML}$ & $\mathrm{ML}$ & $\mathrm{M}$ & $\mathrm{ML}$ & $\mathrm{M}$ & $\mathrm{M}$ & $(0.00,1.80,4.20)$ \\
Tmmeha & $\mathrm{ML}$ & $\mathrm{ML}$ & $\mathrm{M}$ & $\mathrm{M}$ & $\mathrm{ML}$ & $\mathrm{M}$ & $\mathrm{M}$ & $\mathrm{ML}$ & $\mathrm{ML}$ & $\mathrm{ML}$ & $(0.00,1.50,4.00)$ \\
Chhre & $\mathrm{VH}$ & $\mathrm{MH}$ & $\mathrm{H}$ & $\mathrm{MH}$ & $\mathrm{VH}$ & $\mathrm{H}$ & $\mathrm{MH}$ & $\mathrm{H}$ & $\mathrm{MH}$ & $\mathrm{ML}$ & $(4.20,6.80,9.20)$ \\
Chhte & $\mathrm{ML}$ & $\mathrm{M}$ & $\mathrm{M}$ & $\mathrm{ML}$ & $\mathrm{ML}$ & $\mathrm{M}$ & $\mathrm{ML}$ & $\mathrm{M}$ & $\mathrm{M}$ & $\mathrm{ML}$ & $(0.00,1.80,4.20)$ \\
Chhtes & $\mathrm{ML}$ & $\mathrm{ML}$ & $\mathrm{M}$ & $\mathrm{M}$ & $\mathrm{ML}$ & $\mathrm{M}$ & $\mathrm{M}$ & $\mathrm{ML}$ & $\mathrm{ML}$ & $\mathrm{ML}$ & $(0.00,1.50,4.00)$ \\
\hline
\end{tabular}

determines the compromise ranking and the compromise solution under initial weights [33]. The methodology formulates decision-making problem followed by normalization of decision-making information. The techniques construct weighted decision-making matrix via determining of the positive ideal solution and the negative ideal solution of the evaluated stuffs. VIKOR utilized equations (12)-(18) for decision rationalization and evaluation.

The operational rules of the trapezoidal fuzzy numbers $\tilde{a}$ and $\tilde{b}$ are shown as follows Chen et al. (2005):

$r_{i j}=\frac{x_{i j}}{\sqrt{\sum_{j=1}^{n} x^{2} i j}}, i=1,2,3, \ldots \cdots m, j=1,2,3, . \cdots \cdots n$.

For beneficial attributes:

$$
\begin{aligned}
& \tilde{\tilde{V}}^{+}=\left[\tilde{\tilde{v}}_{j}^{+}\right]_{1 \times n}, \\
& \tilde{\mathscr{V}}^{-}=\left[\tilde{\tilde{v}}_{j}^{-}\right]_{1 \times n} .
\end{aligned}
$$

For nonbeneficial attributes:

$$
\begin{aligned}
& \widetilde{\tilde{V}}^{+}=\left[\tilde{\tilde{v}}_{j}^{-}\right]_{1 \times n}, \\
& \tilde{\tilde{V}}^{-}=\left[\tilde{\tilde{v}}_{j}^{+}\right]_{1 \times n}, \\
& \mathcal{S}_{i}=\sum_{j=1}^{n} \frac{d\left(\tilde{\tilde{v}}_{j}^{+}, \tilde{\tilde{v}}_{i j}\right)}{d\left(\tilde{\tilde{v}}_{j}^{+}, \tilde{\tilde{v}}_{j}^{-}\right)}, \\
& \mathscr{R}_{i}=\max _{j}\left[\frac{d\left(\tilde{\tilde{v}}_{j}^{+}, \tilde{\tilde{v}}_{i j}\right)}{d\left(\tilde{\tilde{v}}_{j}^{+}, \tilde{\tilde{v}}_{j}^{-}\right)}\right] \text {, } \\
& Q_{i}=v \frac{\left(\mathcal{S}_{i}-\mathcal{S}^{*}\right)}{\left(\mathcal{S}^{-}-\mathcal{S}^{*}\right)}+(1-v) \frac{\left(\mathscr{R}_{i}-\mathscr{R}^{*}\right)}{\left(\mathscr{R}^{-}-\mathscr{R}^{*}\right)},
\end{aligned}
$$

where $v$ is introduced as weight of the strategy of the majority of criteria or the maximum group utility. Rank the alternatives by sorting the values of in ascending order.

3.3. FMF-Technique-2. It is full multiplicative form of MOORA [27]. It embodies the maximization as well as minimization of multiplicative utility function, where overall utility of $i_{\text {th }}$ alternative is expressed as dimensionless number, and $w_{i}$ is considered as priority weights:

$$
U_{i}^{\prime}=\frac{A_{i}}{B_{i}}
$$

Here, denotes the product of ben $A_{i}=\prod_{j=1}^{g} x_{i j} ; i=1,2$, $\cdots, m$ eficial measures of the $i_{\text {th }}$ alternative to be maximized with $g=1,2, \cdots, n$ being the number of measures to be maximized and $B_{i}=\prod_{j=g+1}^{n} x_{i j} ; i=1,2, \cdots, m$ denotes the product of nonbeneficial measures of the $i_{\text {th }}$ alternative to be minimized with $n-g$ being the number of measures to be minimized.

\section{Case Study}

This is an empirical case study of a TEHES production company, located at the north part of India. The manager of said company had received an order from one of the ECM (Electrical Discharge Machine) workshop/lab to design TEHES of such as material, which has high EAI. The material has capability to absorb or extract the heat from exiting toxic hot soap-linseed-kerosene water coolant after finishing each ECM machining operation, so that after cooling, ECM fluid (due to passing through TEHES) can be reused for machining of the next part. Therefore, the manager of the case study company has instructed the designer for designing TEHESs by mapping the EAI of composite TEHES tube materials under O-S dimensions. The developed and proposed TEHES-O-S-tube material evaluation model for assessing an EAI of composite TEHES tube material is shown in Table 1. 
TABLE 6: Computed defuzzified crisp values of TEHES-O-S-tube material dimensions for assessing EAI.

\begin{tabular}{|c|c|c|c|c|c|c|}
\hline \multirow{2}{*}{ O-S dimensions } & \multirow{2}{*}{$\begin{array}{c}\text { Defuzzified priority } \\
\text { weights/weight crisp value }\end{array}$} & \multicolumn{5}{|c|}{ Defuzzified appropriateness ratings/rating crisp value } \\
\hline & & $\mathrm{J} 4$ & JSLAUS & $\mathrm{J} 204 \mathrm{Cu}$ & $409 \mathrm{M}$ & $\mathrm{J}-304$ \\
\hline Yschht & 5.0 & 0.00 & 0.00 & 0.00 & 0.00 & 0.00 \\
\hline Utschht & 5.2 & 0.00 & 0.00 & 0.00 & 0.00 & 0.00 \\
\hline$\%$ Eht & 5.9 & 0.00 & 0.00 & 0.00 & 0.00 & 0.00 \\
\hline Htchht & 4.8 & 0.00 & 0.00 & 0.00 & 0.00 & 0.00 \\
\hline $\mathrm{C}$ & 3.5 & 0.00 & 0.00 & 0.00 & 0.00 & 0.00 \\
\hline Crrchht & 5.2 & 0.00 & 0.00 & 0.00 & 0.00 & 0.00 \\
\hline Wrchht & 1.9 & 0.00 & 0.00 & 0.00 & 0.00 & 0.00 \\
\hline Tmmeha & 1.7 & 3.2 & 3.9 & 5.5 & 0.5 & 3.2 \\
\hline Chhre & 6.8 & 5.5 & 3.9 & 3.3 & 2.8 & 5.5 \\
\hline Chhte & 1.9 & 3.2 & 5.0 & 5.0 & 5.0 & 3.2 \\
\hline Chhtes & 1.7 & 4.1 & 6.6 & 7.2 & 7.2 & 4.1 \\
\hline
\end{tabular}

TABle 7: Computed normalized values of TEHES-O-S-tube material dimensions for assessing EAI.

\begin{tabular}{|c|c|c|c|c|c|}
\hline O-S-dimensions & $\mathrm{J} 4$ & JSLAUS & $\mathrm{J} 204 \mathrm{Cu}$ & $409 \mathrm{M}$ & $J-304$ \\
\hline Yschht & 0.480 & 0.528 & 0.522 & 0.339 & 0.322 \\
\hline Utschht & 0.473 & 0.514 & 0.517 & 0.296 & 0.397 \\
\hline$\%$ Eht & 0.416 & 0.503 & 0.477 & 0.277 & 0.520 \\
\hline Htchht & 0.480 & 0.475 & 0.470 & 0.382 & 0.421 \\
\hline C & 0.333 & 0.625 & 0.357 & 0.548 & 0.265 \\
\hline Crrchht & 0.300 & 0.581 & 0.094 & 0.750 & 0.019 \\
\hline Wrchht & 0.417 & 0.399 & 0.379 & 0.607 & 0.393 \\
\hline Tmmeha & 0.480 & 0.475 & 0.470 & 0.382 & 0.480 \\
\hline Chhre & 0.333 & 0.625 & 0.357 & 0.548 & 0.333 \\
\hline Chhte & 0.300 & 0.581 & 0.094 & 0.750 & 0.300 \\
\hline Chhtes & 0.417 & 0.399 & 0.379 & 0.607 & 0.417 \\
\hline
\end{tabular}

TABLE 8: Computed values of linking TEHES-O-S-tube material dimensions for assessing EAI.

\begin{tabular}{|c|c|c|c|c|c|}
\hline O-S-dimensions & $\mathrm{J} 4$ & JSLAUS & $\mathrm{J} 204 \mathrm{Cu}$ & $409 \mathrm{M}$ & $\mathrm{J}-304$ \\
\hline Yschht & 0.232 & 0.000 & 0.031 & 0.915 & 1.000 \\
\hline Utschht & 0.197 & 0.015 & $0.00 S_{i} 0$ & 1.000 & 0.544 \\
\hline$\%$ Eht & 0.573 & 0.930 & 0.823 & 0.000 & 1.001 \\
\hline Htchht & 0.000 & 0.051 & 0.101 & 1.000 & 0.601 \\
\hline C & 0.190 & 1.000 & 0.256 & 0.785 & 0.000 \\
\hline Crrchht & 0.384 & 0.769 & 0.102 & 1.000 & 0.000 \\
\hline Wrchht & 0.168 & 0.088 & 0.000 & 1.001 & 0.061 \\
\hline Tmmeha & 0.015 & 0.000 & 1.000 & 0.015 & 0.480 \\
\hline Chhre & 0.930 & 0.823 & 0.000 & 0.930 & 0.333 \\
\hline Chhte & 0.051 & 0.101 & 1.000 & 0.051 & 0.300 \\
\hline Chhtes & 0.417 & 0.399 & 0.379 & 0.607 & 0.417 \\
\hline
\end{tabular}

4.1. The Further Steps Are Depicted Here. Step 1. 100 experts pertaining to different cross-functional departments of said case study company voluntarily participated in that context and provided valuable insights. The Research and Development RND body of company had introduced five alloy composite materials such as J4, JSLAUS, J204Cu, 409 M, and J-304 for assessment and evaluation of EAI under
O-S-dimensions depicted in Table 1. The cost and other parameters/characteristics of J4, JSLAUS, J204Cu, $409 \mathrm{M}$, and J-304 alloy composite material are presented corresponding to alternative composite TEHES tube materials in Table 2.

Step 2. After finalizing the set of TEHES composite tube materials, two members from each depicting departments 
TABLE 9: Computed weight stabilize values of $S_{i}$ linking TEHES-O-S-tube material dimensions for assessing EAI.

\begin{tabular}{|c|c|c|c|c|c|}
\hline O-S-dimensions & $\mathrm{J} 4$ & JSLAUS & $\mathrm{J} 204 \mathrm{Cu}$ & $409 \mathrm{M}$ & $\mathrm{J}-304$ \\
\hline Yschht & 0.154 & 0.000 & 0.020 & 0.606 & 0.662 \\
\hline Utschht & 0.132 & 0.010 & 0.000 & 0.668 & 0.364 \\
\hline$\%$ Eht & 0.487 & 0.791 & 0.700 & 0.000 & 0.852 \\
\hline Htchht & 0.000 & 0.036 & 0.071 & 0.701 & 0.422 \\
\hline $\mathrm{C}$ & 0.063 & 0.333 & 0.085 & 0.262 & 0.000 \\
\hline Crrchht & 0.306 & 0.612 & 0.081 & 0.795 & 0.000 \\
\hline Wrchht & 0.073 & 0.038 & 0.000 & 0.434 & 0.027 \\
\hline Tmmeha & 0.154 & 0.000 & 0.020 & 0.606 & 0.662 \\
\hline Chhre & 0.132 & 0.010 & 0.000 & 0.668 & 0.364 \\
\hline Chhte & 0.487 & 0.791 & 0.700 & 0.000 & 0.852 \\
\hline Chhtes & 0.000 & 0.036 & 0.071 & 0.701 & 0.422 \\
\hline
\end{tabular}

TABLE 10: Tabulated cumulative values EAI with rankings.

\begin{tabular}{lccccccc}
\hline $\begin{array}{l}\text { Energy Absorbability Index } \\
\text { (EAI) of alternatives }\end{array}$ & $S_{i}$ & $R_{i}$ & $\begin{array}{c}\text { Performance index } \\
(\nu=0.5) \\
\text { VIKOR-technique }\end{array}$ & Ranking & $\begin{array}{c}\text { Performance index } \\
\text { FMF-technique }\end{array}$ & $\begin{array}{c}\text { Ranking } \\
\text { Comparative analysis } \\
\text { Dominance theory }\end{array}$ \\
\hline J4 & 1.214 & 0.487 & 0.0511 & 1 & 0.0019 & 1 & 1 \\
JSLAUS & 1.820 & 0.791 & 0.5886 & 3 & 0.0013 & 3 & 2 \\
J204Cu & 0.958 & 0.700 & 0.2917 & 2 & 0.0015 & 5 & 5 \\
$409 \mathrm{M}$ & 3.465 & 0.795 & 0.9228 & 5 & 0.0010 & 4 & 4 \\
J-304 & 2.325 & 0.852 & 0.7727 & 4 & 0.0012 & 4 & 4 \\
\hline
\end{tabular}

such as environmental, heat analysis, design, safety, and production of case study company were invited to choose a linguistic variable scale for assigning rating against only $S$ dimensions of TEHES composite tube materials. The expert's panel elected a five-point TFN scale, shown in Table 3 for modelling S-dimensions. The appropriateness ratings or quotation against only $\mathrm{O}$ tube material dimensions was proposed vs. five alternative composite TEHES tube materials, i.e., J4, JSLAUS, J204Cu, 409 M, and J-304 by $\mathrm{RND}$, and finally, data of $\mathrm{O}$ is mixed with $\mathrm{S}$ tube material dimensions to formulate problem, shown in Table 2.

Step 3. Later, the appropriateness subjective ratings against $\mathrm{S}$-tube material dimensions and priority weights against all O-S-ph tube material dimensions, assigned by experts, are revealed in Tables 4 and 5 .

Step 4. After evaluating TFN variables from the expert's panel, equations (5) and (9) were used to aggregate the fuzzy set and formulate the TEHES composite tube material evaluation problem, revealed in Tables 4 and 5. Next, the fuzzy data is transformed into crisp value or defuzzified by using equation (11), revealed in Table 6.

Step 5. The normalization of dimensions of TEHES composite tube materials is carried out by using equation (12); the computed values are shown in Table 7 . Next, the values of $S_{i}$ linking decision measures are computed by using equations (14)-(16), revealed in Table 8 , and $Q_{i}$ is determined by using equations (17) and (18), revealed in Table 9.

Step 6. Next, the full multiplicative form, equation (19), was applied on normalized values of Table 7 and multiplied

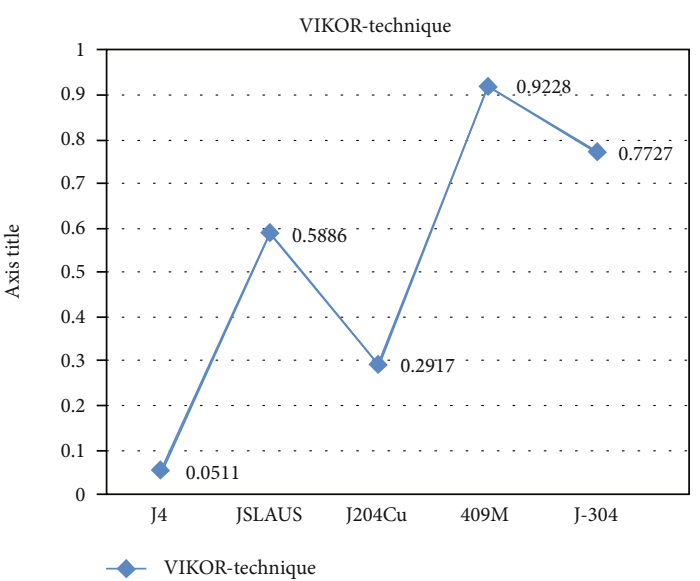

FIgURE 1: Crisp VIKOR application for evaluating EAI of TEHES tube materials under TEHES-O-S-tube material evaluation dimensions.

with weights to evaluate the preference orders of TEHES composite tube materials. The results are shown in Table 10.

Step 7. It is discussed that reliability of results is a major concern in the presented research forum. The J4 TEHES composite tube material had the rich EAI under TEHESO-S-dimensions to control GWAP, which is computed by application of dominance theory. The results are shown in Table 10 


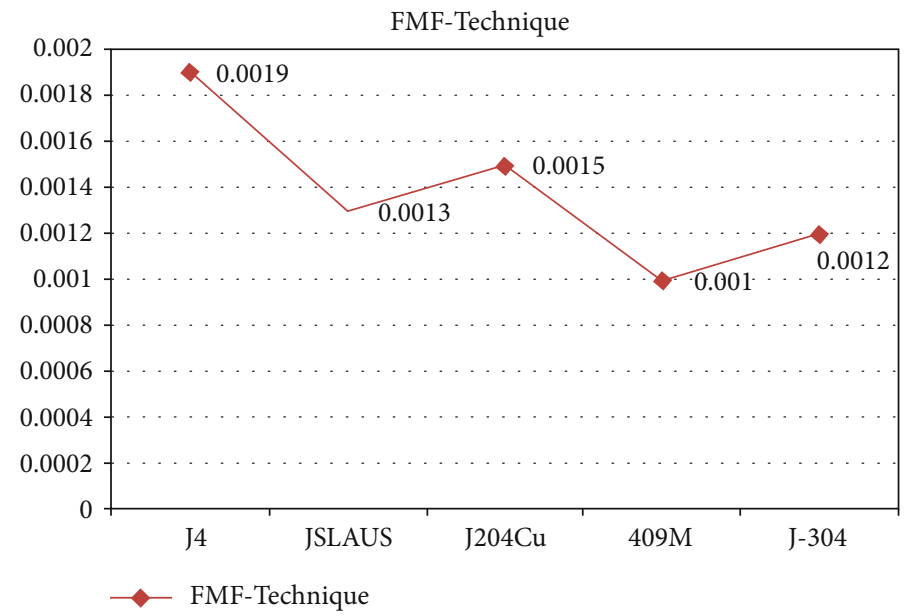

FIGURE 2: Crisp-FMF application for evaluating EAI of TEHES tube material under TEHES-O-S-tube material evaluation dimensions.

\section{Discussions and Result Graphical Representations}

The evaluation and selection of high EAI of composite TEHES tube material under umbrella of O-S-tube material dimensions (to reduce $\mathrm{CHH}$ loss) are ascertained as the complex and difficult task. As it is investigated by TEHES designers and researchers that preferable alternative selection is not a straightforward process as the acquired results can be sensitive, it is critical and leads to system success or failure. It is determined that unsuccessful elected composite TEHES tube materials not only increase the emission of $\mathrm{CHH}$ loss towards environment during toxic fluid circulation across TEHESs but also increase the manufacturing cost and unnecessarily maintenance costs and causes of GWAP.

Nowadays, companies are attempting to design their TEHESs in such a way, where TEHESs can reduce the GWAP by maximizing heat transfers between two toxic fluids with zero $\mathrm{CHH}$ emission, rich efficiency (good output), etc. The same can be achieved by engrossing and selecting the high EAI composite TEHES tube material, technologies, means, new products into existing manufacturing systems, said by $([1,9,10,34]$. The same is attempted in the presented research work as discussed.

In the presented research work as we discussed, a mixed mathematical modelling of the O-S (objective-subjective-) dimension model with an integrated approach embedded with dominance theory is proposed for evaluating the EAI of composite TEHES tube material to control and minimizing GWAP and green management vice vera. As a part of analysis, in the case study (Section 4), the designer was requested to use J4 from available materials such as JSLAUS, J204Cu, 409 M, and J-304 from green management and economic perspectives to build TEHES for extracting the heat from exiting toxic hot soap-linseed-kerosene water coolant after finishing each ECM operation. The results are tabulated in Table 10, the graphical representation (Figures 1 and 2) depicted the results, and however, dominance technique is applied additional for obtaining accurate results as discussed.

\section{Conclusion}

The evaluation of high EAI-composite TEHES tube material and then selection under O-S-tube material dimensions (mixed modelling) is a crucial phase. The appropriate high EAI-composite TEHES tube material evaluation and selection under both dimensions (mixed modelling) leads towards the success of TEHES production companies. In the presented research work, the efforts are implicated to develop and propose a TEHES-O-S-tube material evaluation model for assessing EAI and economically electing efficient TEHES tube material from available domains under O-S-ph dimensions. In the presented research work, the same is targeted by the authors by assessing the high EAI of TEHES composite TEHES tube material under TEHES-O-S-tube material dimensions. As discussed, the proposed TEHES-O-S-tube material evaluation model for assessing EAI consisted of five grades of TEHES composite tube materials, i.e., J4, JSLAUS, J204Cu, $409 \mathrm{M}$, and J-304. The RND department proposed materials to TEHES designer to examine them and assess that which is the best to fabricate TEHES under seven TEHES-Otube material evaluation dimensions, i.e., Yschht, Utschht, \% Eht, Htchht, C, Crrchht, and Wrchht in conjunctive with four TEHES-S-tube material evaluation dimensions, i.e., Tmmeha, Chhre, Chhte, and Chhtes. The solution is found by using integrated crisp-FMF-VIKOR techniques with dominance theory, where Yschht, Utschht, Htchht, Tmmeha, Chhre, Chhte, and Chhtes replicate beneficial dimension and $\%$ Eht, C, Crrchht, and Wrchht replicate nonbeneficial dimension. After the technical steps of integrated FMFVIKOR techniques, it is found that TEHES-tube material J4 is prioritized as the best alternative on the application of crisp VIKOR and the next same alterative is also suggested on the application of crisp FMF. To conformity, the dominance theory is implicated to respond towards significant alternative TEHES-tube material evaluation; therefore, dominance theory also concluded same J4 alternative material. The case study company is advised to choose J4 to fabricate TEHES, has high EAI under mixed modelling (O-S) dimensions, and shall be fine for extracting the heat from exiting toxic 
hot soap-linseed-kerosene water coolant after finishing each ECM operation. The research work provided the two innovative solutions to TEHES designers such as choose the economic/cost TEHESs and initiate to green management (reducing minimizing the GWAP). From future perspective, the forthcoming or advanced materials to be tested for fabricating the TEHESs can be investigated under proposed model (O-S) dimensions on replacement of O-S data.

\section{Data Availability}

The data used to support the findings of this study are available in Table 10.

\section{Conflicts of Interest}

The authors declare that there is no conflict of interest regarding the publication of this manuscript.

\section{Acknowledgments}

The paper is prepared by research employment.

\section{References}

[1] X. Qin, G. Huang, A. Chakma, X. Nie, and Q. Lin, "A MCDMbased expert system for climate-change impact assessment and adaptation planning - A case study for the Georgia Basin, Canada," Canada, Expert Systems with Applications, vol. 34, no. 3, pp. 2164-2179, 2008.

[2] P. Konidari and D. Mavrakis, "A multi-criteria evaluation method for climate change mitigation policy instruments," Energy Policy, vol. 35, no. 12, pp. 6235-6257, 2007.

[3] V. P. Darji and R. V. Rao, "Intelligent multi criteria decision making methods for material selection in sugar industry," Procedia Materials Science, vol. 5, pp. 2585-2594, 2014.

[4] E. K. Zavadskas, Z. Turskis, and T. Vilutiene, "Multiple criteria analysis of foundation instalment alternatives by applying additive ratio assessment (ARAS) method," Archives of Civil and Mechanical Engineering, vol. 10, no. 3, pp. 123-141, 2010.

[5] A. S. Milani, A. Shanian, R. Mandoliat, and J. A. Nemes, "The effect of normalization norms in multiple attribute decision making models: a case study in gear material selection," Structural and Multidisciplinary Optimization, vol. 29, no. 4, pp. 312-318, 2005.

[6] L. Anojkumar, M. Ilangkumaran, and V. Sasirekha, "Comparative analysis of MCDM methods for pipe material selection in sugar industry," Expert Systems with Applications, vol. 41, pp. 2964-2980, 2014.

[7] E. Zumelzu, C. Cabezas, O. Optitz, E. Quiroz, L. Goyos, and A. Parada, "Microstructural characteristics and corrosion behavior of high chromium cast iron alloys in sugar media," Protection of Metals, vol. 39, no. 2, pp. 183-188, 2003.

[8] Z. P. Fan, X. Zhang, F. D. Chen, and Y. Liu, "Extended TODIM method for hybrid multiple attribute decision making problems,” Knowledge-Based Systems, vol. 42, pp. 40-48, 2013.

[9] M. K. Rathod and H. V. Kanzaria, "A methodological concept for phase change material selection based on multiple criteria decision analysis with and without fuzzy environment," Material and Design, vol. 32, no. 6, pp. 3578-3585, 2011.
[10] S. R. Maitya and S. Chakraborty, "Grinding wheel abrasive material selection by using fuzzy AHP and TOPSIS technique," International Journal of Humanities and Social Science, vol. 1, no. 3, pp. 135-140, 2013.

[11] C. H. Wang, I. Y. Lu, and C. B. Chen, "Integrating hierarchical balanced scorecard with non-additive fuzzy integral for evaluating high technology firm performance," International Journal of Production Economics, vol. 128, no. 1, pp. 413-426, 2010.

[12] R. W. Christian, B. Christian, and O. R. Andreas, "Influence of treatment temperature and duration on selected biological, mechanical, physical and optical properties of thermally modified timber," Wood Material Science \& Engineering, vol. 2, no. 2, pp. 66-76, 2007.

[13] D. T. Dang, N. D. A. Pham, and T. N. Phan, "Determine the special term of a two-dimensional heat source," Applicable Analysis, vol. 88, no. 3, pp. 457-474, 2009.

[14] N. Prakash, H. M. Karan, H. S. Mostafa, M. Z. Syed, and H. L. V. John, "Energy effectiveness of simultaneous heat and mass exchange devices," Frontiers in Heat and Mass Transfer (FHMT), 2010

[15] A. Loganathan and M. Ilangkumaran, "Decision making methodology for heat sink material selection using a compromise ranking and outranking method under fuzzy environment," Journal of Advances in Chemistry, vol. 12, no. 12, pp. 4564-4575, 2016.

[16] P. Reeju, "Overview of high-energy x-ray diffraction microscopy (HEDM) for mesoscale material characterization in three-dimensions," in Materials Discovery and Design, pp. 167-201, Springer, Cham, 2018.

[17] R. Uttamm and M. Mrinmoy, "Productivity yielding in shell and tube heat exchanger by MCDM-NBO approach," Measurement and Control, vol. 52, no. 3-4, pp. 262-275, 2019.

[18] H. Messaoud, A. Benaoumeur, C. Xavier et al., "Numerical analysis of a solar tower receiver novel design," Sustainability, vol. 12, no. 17, p. 6957, 2020.

[19] L. Zhengyi and S. Zheng, "The nelson-seiberg theorem generalized with nonpolynomial superpotentials," Advances in High Energy Physics, vol. 2020, Article ID 3701943, 6 pages, 2020.

[20] A. Tripathi, B. Chauhan, A. K. Rao, and R. P. Malik, "Massive spinning relativistic particle: revisited under brst and supervariable approaches," Advances in High Energy Physics, vol. 2020, Article ID 1236518, 25 pages, 2020.

[21] Q. Wang and F. H. Liu, "Excitation function of initial temperature of heavy flavor quarkonium emission source in high energy collisions," Advances in High Energy Physics, vol. 2020, Article ID 5031494, 31 pages, 2020.

[22] K. B. Aroon, "Quantum spectrum of tachyonic black holes in a brane-anti-brane system," Advances in High Energy Physics, vol. 2020, Article ID 6570890, 6 pages, 2020.

[23] Z. Y. Wang, "Mass or energy: on charge of gravity," Advances in High Energy Physics, vol. 2020, Article ID 8202609, 8 pages, 2020.

[24] K. C. Girish, K. Najimuddin, and M. Subhendra, "Super gravity model of inflation and explaining icecube hese data via pev dark matter decay," Advances in High Energy Physics, vol. 2020, Article ID 2478190, 14 pages, 2020.

[25] A. Guitouni and J. Martel, “Tentative guidelines to help choosing an appropriate MCDA method," European Journal of Operational Research, vol. 109, no. 2, pp. 501-521, 1998. 
[26] L. A. Zadeh, "Fuzzy sets," Information and Control, vol. 8, no. 3, pp. 338-353, 1965.

[27] A. K. Sahu, H. K. Narang, M. S. Rajput, N. K. Sahu, and A. K. Sahu, "Performance modeling and benchmarking of green supply chain management," Benchmarking: An International Journal, vol. 25, no. 7, pp. 2248-2271, 2018.

[28] A. K. Sahu, N. K. Sahu, and A. K. Sahu, "Benchmarking CNC machine tool using Hybrid-Fuzzy methodology," International Journal of Fuzzy System Applications, vol. 4, no. 2, pp. 28-46, 2015.

[29] K. Tanaka, An Introduction to Fuzzy Logic for Practical Applications, Springer-Verlag, New York, NY, 1997.

[30] L. A. Zadeh, "The concept of a linguistic variable and its application to approximate reasoning-I," Information Sciences, vol. 8, no. 3, pp. 199-249, 1975.

[31] A. K. Sahu, N. K. Sahu, and A. K. Sahu, "Fuzziness: a mathematical tool," in Theoretical and Practical Advancements for Fuzzy System Integration, pp. 1-30, IGI Global, 2017.

[32] P. P. Mohanty and S. S. Mahapatra, "A compromise solution by VIKOR method for ergonomically designed product with optimal set of design characteristics," Procedia Materials Science, vol. 6, pp. 633-640, 2014.

[33] M. K. Sayadi, M. Heydari, and K. Shahanaghi, "Extension of VIKOR method for decision making problem with interval numbers," Applied Mathematical Modelling, vol. 33, no. 5, pp. 2257-2262, 2009.

[34] E. Thanassoulis, M. Kortelainen, and R. Allen, "Improving envelopment in data envelopment analysis under variable returns to scale," European Journal of Operational Research, vol. 218, no. 1, pp. 175-185, 2012. 